\section{Immunohistochemistry detected and localized cannabinoid receptor type 2 in bovine fetal pancreas at late gestation}

Cecilia Dall'Aglio, ${ }^{1}$ Angela Polisca, ${ }^{1}$

Maria Grazia Cappai, ${ }^{2}$

Francesca Mercati, ${ }^{1}$ Alessandro Troisi, ${ }^{1}$

Carolina Pirino, ${ }^{1}$ Paola Scocco, ${ }^{3}$

Margherita Maranesi ${ }^{1}$

${ }^{1}$ Department of Veterinary Medicine, University of Perugia

${ }^{2}$ Department of Agricultural Sciences, University of Sassari

${ }^{3}$ School of Biosciences and Veterinary Medicine, University of Camerino, Italy

\section{Abstract}

At present, data on the endocannabinoid system expression and distribution in the pancreatic gland appear scarce and controversial as descriptions are limited to humans and laboratory animals. Since the bovine pancreas is very similar to the human in endocrine portion development and control, studies on the fetal gland could prove to be very interesting, as an abnormal maternal condition during late pregnancy may be a predisposing trigger for adult metabolic disorders. The present investigation studied cannabinoid receptor type 2 presence and distribution in the bovine fetal pancreas towards the end of gestation. Histological analyses revealed numerous endocrinal cell clusters or islets which were distributed among exocrine adenomeri in connectival tissue. Immunohistochemistry showed that endocrine-islets contained some CB2-positive cells with a very peculiar localization that is a few primarily localized at the edges of islets and some of them also scattered in the center of the cluster. Characteristically, also the epithelium of the excretory ducts and the smooth muscle layers of the smaller arteries, in the interlobular glandular septa, tested positive for the CB2 endocannabinoid receptor. Consequently, the endocannabinoid system, via the cannabinoid receptor type 2, was hypothesized to play a major role in controlling pancreas function from normal fetal development to correct metabolic functioning in adulthood.

\section{Introduction}

The 'endogenous cannabinoid system', which connects the gastrointestinal apparatus and the hypothalamus, plays a role in controlling several physiological functions of central and peripheral organs. As a complex molecular system, it includes several lipidic molecules or endo-cannabinoids that bind to specific receptors ( $\mathrm{CB} 1$ and $\mathrm{CB} 2$ ) as well as the many enzymes that are involved in cannabinoid biosynthesis and inactivation.

The CB2 cannabinoid receptor is much less common in the body than CB1 but it is certainly expressed in the immune system, hematopoietic cells and even, according to recent studies, in some brain regions ${ }^{1}$ and other peripheral organs and tissues. $^{2-5}$

In particular, in male and female adults, CB2 receptors were detected in the endocrine pancreas of humans and laboratory animals, ${ }^{3,6}$ thus providing further evidence to support the importance of the cannabinoid system in regulating the energy balance, given the endocrine role of the pancreas in insulin and glucagon incretion, control of serum glucose concentrations $^{7}$ and consequent cell utilization. Moreover, a recent study evidenced the importance of endocannabinoids in the control of cell proliferation and organization, with a particular look to the fetal pancreas development. ${ }^{8}$ However, the expression of the components of the endocannabinoid system in the pancreas still needs to be elucidated because often there is no consensus on its distribution in the endocrine islets, for which descriptions are starkly contrasting, especially between animals of different species, such as rats and mice. ${ }^{9,10}$ Moreover, in human pancreas the $\mathrm{CB} 2$ receptor was also found in the exocrine pancreas, unlike what had been previously reported for laboratory animals. ${ }^{6,11}$

Since no data are available on CB2 receptor distribution in the pancreas of pet animals and livestock, the present investigation was designed to fill this gap and to contribute to clear up the discrepancies highlighted by many reports in the literature. In opening this new field of investigation in domestic animals, we decided to start by mapping the distribution of CB2 receptors in the pancreas of bovine fetuses as this species is expected to be closer to humans than laboratory animals in the development of different types of endocrine cells ${ }^{12}$ and in the mechanisms controlling pancreatic development. ${ }^{13}$ The
Correspondence: Cecilia Dall'Aglio, Department of Veterinary Medicine, University of Perugia, Via San Costanzo 4, 06126 Perugia, Italy.

Tel. +39.075.5857635 - Fax: +39.075.5857631. E-mail: cecilia.dallaglio@unipg.it

Key words: Cattle; cannabinoids; immunohistochemistry; fetus.

Conflict of interest: none of the Authors has conflict of interest to declare.

Contributions: CDA, MM, immunohistochemical studies; AP, AT, visited animals and collected samples; MGC, CP, manuscript drafting; FM, PS, manuscript revision; CDA, work supervision.

Acknowledgments: the Authors wish to thank Dr. Paola Coliolo for her excellent technical assistance and Mrs. Geraldine Anne Boyd for the revision of the English text.

Received for publication: 16 December 2016. Accepted for publication: 13 February 2017.

This work is licensed under a Creative Commons Attribution-NonCommercial 4.0 International License (CC BY-NC 4.0).

(C) Copyright C. Dall'Aglio et al., 2017

Licensee PAGEPress, Italy

European Journal of Histochemistry 2017; 61:2761 doi:10.4081/ejh.2017.2761

decision to focus on the pancreas of fetuses derived from the concept of 'fetal programming', which encompasses not only environmental, but also maternal influences. The maternal metabolic status exposes the fetus to complex factors that condition gene expression (epigenetics) and fetal metabolism overall, particularly in the late stage of gestation. In fact, the so-called 'transition period', which identifies the late pregnancy and the early lactation in cows, is a critical time in the management of both cow and calf ${ }^{14}$ as, unless correct, it can affect the offspring, with the risk of congenital diseases appearing in adulthood. ${ }^{15}$

\section{Materials and Methods}

After emergency slaughter, 5 bovine fetuses at the $8^{\text {th }}$ month of gestation, were collected and examined. All procedures were carried out following Italian legislation on animal care (DL n.116, 21/01/1992). Each pregnant uterus was 
immediately transported to the necropsy room at the Department of Veterinary Medicine. Each fetus was dissected and pancreas samples were immediately fixed by immersion in a $4 \%$ formaldehyde solution, to be subsequently processed for embedding in paraffin wax. To assess morphometry some sections were processed by hematoxylin-eosin staining. The immunohistochemical sites were visualized using the following reagents: normal goat serum (1:10, sc-2043; Santa Cruz Biotechnology, Santa Cruz, CA, USA), anti-CB2 rabbit polyclonal antibody (1:100, sc-25494; Santa Cruz Biotechnology), biotinylated goat antirabbit IgG (1:200, AP132B; Chemicon, Temecula, CA, USA), avidin-biotin-complex (ABC KIT, PK-6100, Vector Lab., Inc., Burlingame, CA, USA) and diaminobenzidine (DAB, SK-4100, Vector Lab., Inc.) as the chromogen. The primary antibody sc-25494, anti-CB2, was recommended for bovine tissues by the manufacturer, showing a high percentage of homology (around 85\%) between human and bovine, and was already used in a study using bovine tissue. ${ }^{16}$

Briefly, dewaxed sections were microwaved for $15 \mathrm{~min}$ in $10 \mathrm{mM}$ citric acid for antigen retrieval and, after proper cooling, were incubated with normal serum for $30 \mathrm{~min}$. The following step concerned the incubation overnight with the primary antibody. The next day, after washing in PBS, sections were incubated with the secondary biotin-conjugated anti- body for $30 \mathrm{~min}$ and subsequently, for other 30 min, with the ABC kit. The reaction was visualized using the chromogen solution and then sections were dehydrated and mounted in natural Canada balsam
(BDH, Poole, UK). On serial sections, a morphometric analysis was conducted to better border the endocrine area and so identify the CB2-positive cells as endocrine-cells.

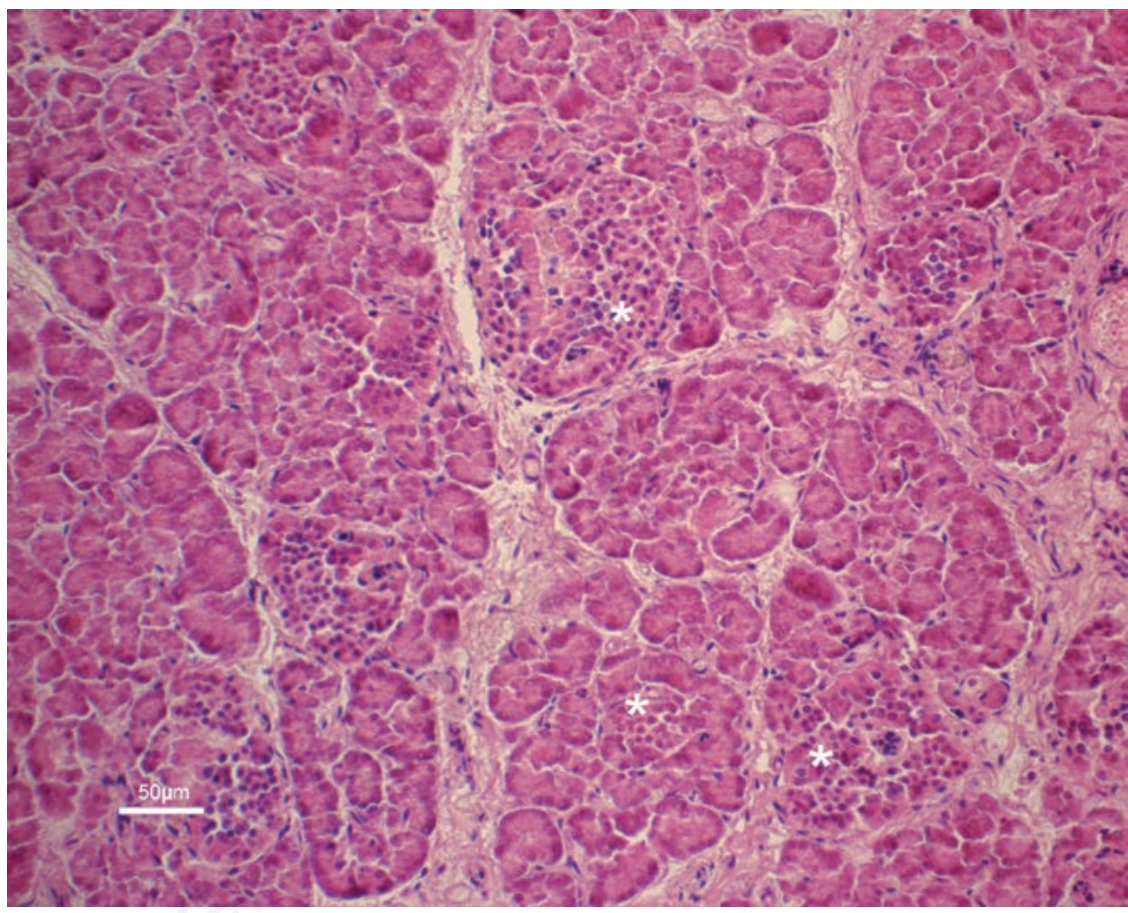

Figure 1. Light microphotograph of the pancreas of bovine fetus at the $8^{\text {th }}$ month of gestation: many ovoid or round endocrine cell clusters are evident (asterisks) throughout the exocrine parenchyma. Hematoxylin-eosin staining.
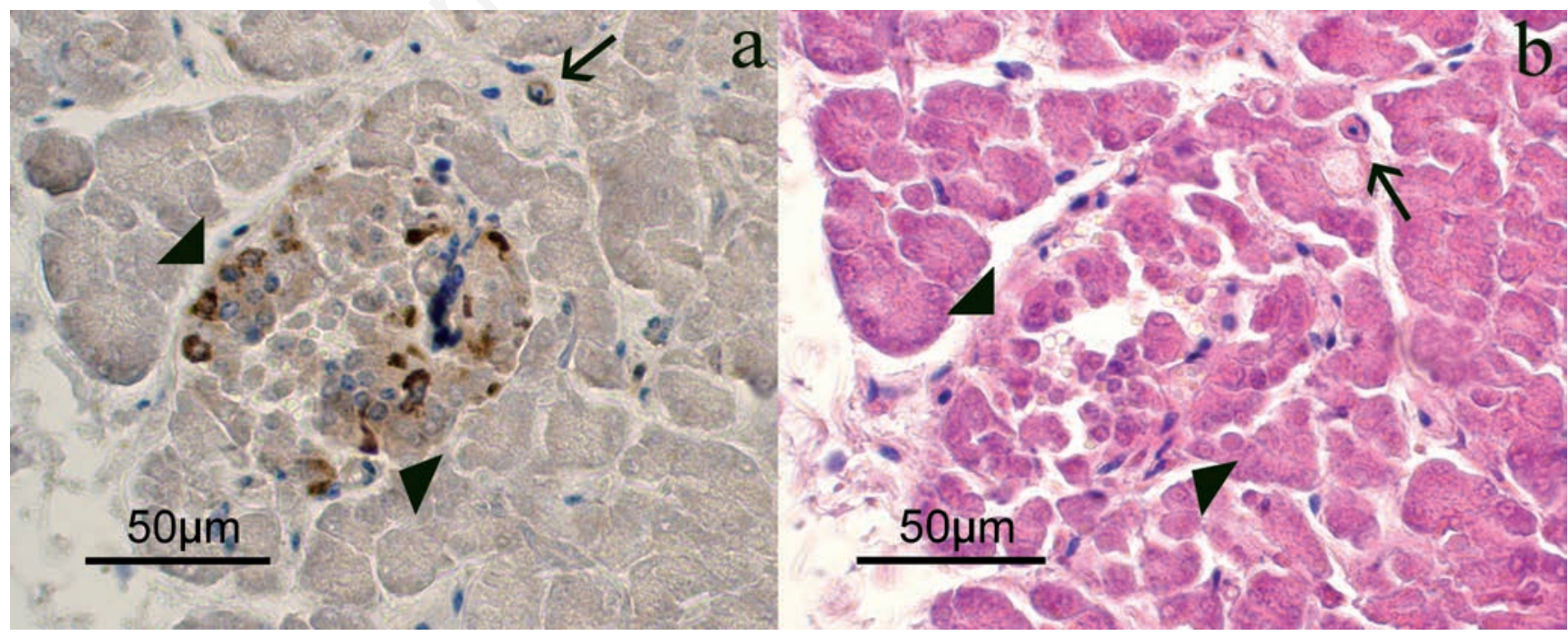

Figure 2. Serial sections that identify the endocrine portion (arrows-head) and the presence of some isolated cells (arrow), where it is possible to observe the immunopositivity for CB2. a) CB2 immunopositivity. b) Hematoxylin-eosin. 
Sections with PBS instead of primary antibodies were used as controls of unspecific staining. Sections of bovine spleen were used as a positive control for CB2 antibody. To score the immunohistochemical results, the endocrine cells were con- sidered positive for CB2 only when cytoplasmic staining was evident, independently of its immunointensity.

In order to determine the CB2labelling index, the percentage of positive CB2 cells for each fetus was determined.
All tissue analyses were carried out on coded slides using a light microscope (Nikon Eclipse E800) connected to a digital camera (Dxm 1200 Nikon digital camera).
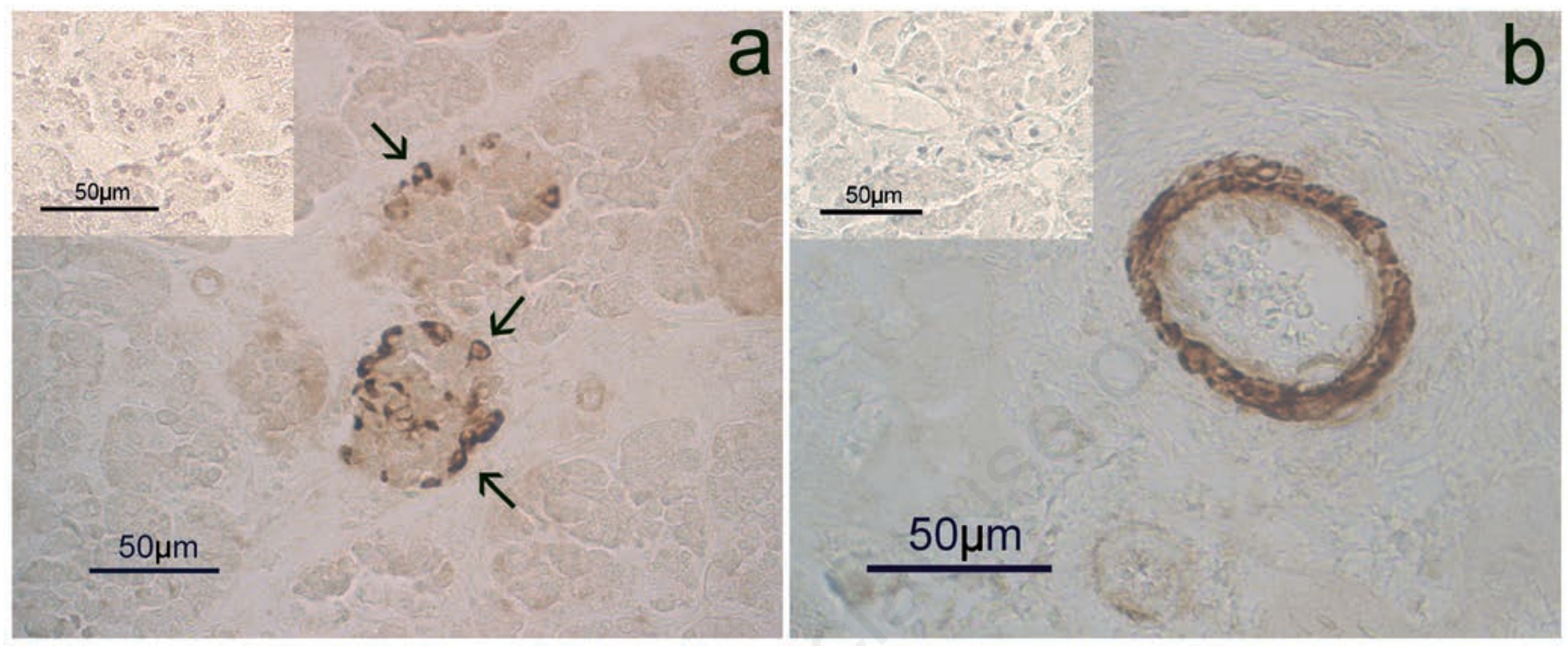

Figure 3. CB2 immunohistochemistry in the pancreas of bovine fetuses. Immunopositivity is localized in the cytoplasm of some endocrine cells (a), mainly at the edge of the endocrine islands (arrows). b) CB2 immunopositivity also localized in the muscular layer of the connective arteries. The inserts are examples of immunohistochemical sections negative for CB2 in which the primary antibody was omitted.

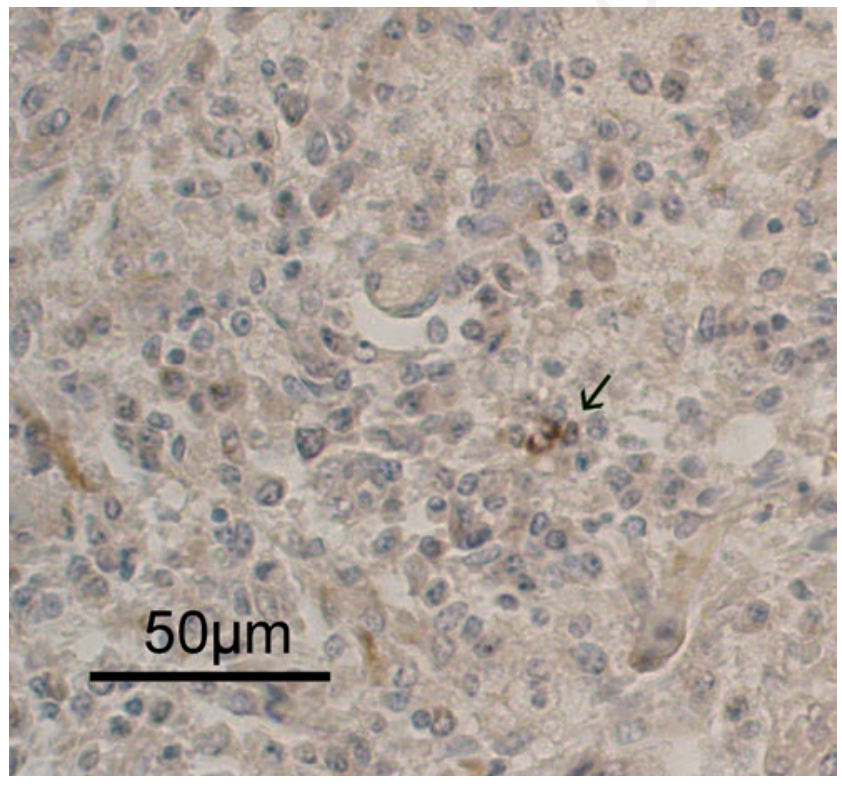

Figure 4. CB2-immunopositivity in the bovine spleen: positive control.

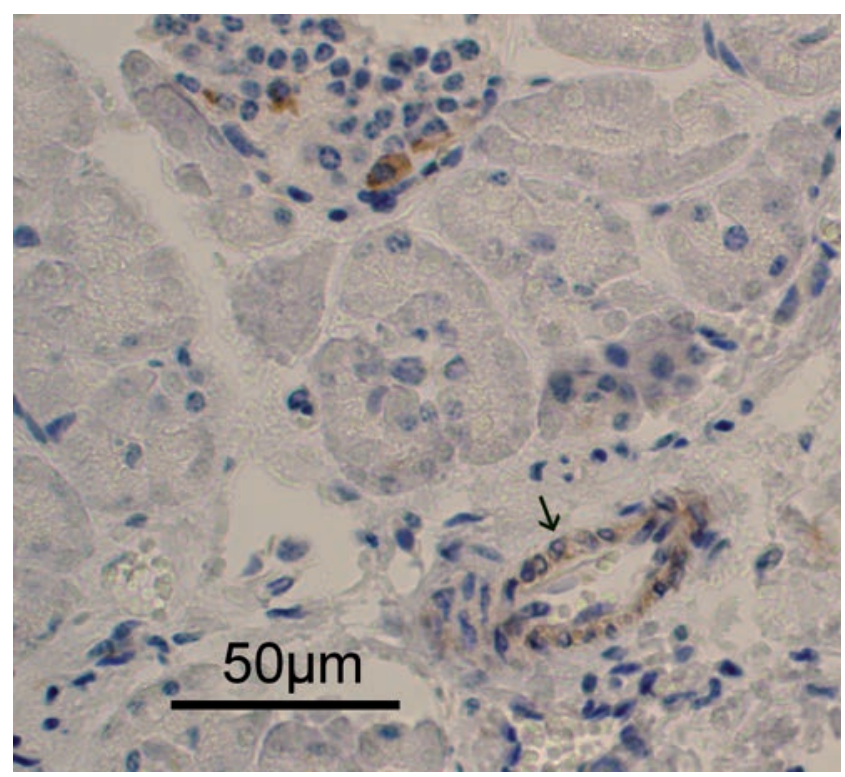

Figure 5. CB2-immunopositivity in the epithelial cells of the exocrine ducts. 


\section{Results}

Hematoxylin-eosin stained tissues revealed many ovoid or round endocrine cell clusters, scattered throughout the exocrine parenchyma (Figure 1, asterisks). Single endocrine cells were occasionally observed scattered throughout the exocrine gland (Figure 2 a,b, arrows). Positive immunoreaction (IR) for CB2 (Figures 2a and 3) was found in the cytoplasm of the endocrine cells. In particular, in the endocrine clusters, some of the endocrine cells on the edges of the clusters (Figure 3a, arrows), were cytoplasmic CB2+ as well as some of them were also scattered in the center of the cluster.

Overall, the immunopositivity for CB2 was observed in $4-10 \%$ of endocrine cells. Moreover, positive staining for CB2 was observed in the muscle layer cells of the small arteries supplying the pancreatic parenchyma (Figure $3 \mathrm{~b}$ ) and in some control sections of bovine spleen (Figure 4). Occasionally, a positive CB2 immunoreaction was also observed in the epithelial cells of ducts (Figure 5, arrow). Staining was completely absent in the control sections, using PBS (insert in Figure 3).

\section{Discussion}

The pancreas is a complex gland. Its exocrine portion produces digestive enzymes and active peptides for the luminal content of duodenum (pancreatic juice), while its endocrine portion produces and incretes particular hormones into the bloodstream, some of which control circulating glucose concentrations in serum and glucose utilization by cells.

During embryogenesis, pancreatic development starts from ventral and dorsal portions of the endoderm which, despite being initially separated, follow the stomach and duodenum rotation, and then merge to form one single organ. Although the two secreting portions of the pancreas develop in diverse phases in the different species, the endocrine portion generally precedes the exocrine and is controlled by a complex sequence of actions of transcription factors. ${ }^{17}$

As far as we know, this is the first report describing CB2 receptor expression and localization in the pancreas of domestic animals, notably bovine fetuses. Immunohistochemistry showed a very peculiar distribution of $\mathrm{CB} 2$ receptor in fetal endocrine islets. CB2+ cells were detected on the edges of clusters and scat- tered without a precise location in the center of islets.

Interestingly, the CB2 receptor was found in the epithelial cells of excretory ducts and in the smooth muscle cells of the arteries within the interlobular pancreatic connective septa, concurring with observations in laboratory animals..$^{6,18}$

Although CB2 receptor is described as membrane receptor and is effectively a transmembrane protein, it is common, as demonstrated in this study, to see immunohistochemical reactions in cytoplasm. As already stated ${ }^{19,20}$ for CB1 receptor, this kind of receptor protein shuttles permanently between plasma membrane and cytoplasm with, very often, a predominantly intracellular localization.

In conclusion, given the distribution patterns we detected, we hypothesize that the cannabinoid molecules are implicated in control of gland functioning as already observed and demonstrated in laboratory animals, ${ }^{8}$ probably by acting on some endocrine cells, epithelial excretory ducts and on small arterial vessel walls as the cannabinoid CB2 receptor was detected in these sites.

\section{References}

1. Van Sickle MD, Duncan M, Kingsley PJ, Mouihate A, Urbani P, Mackie K, et al. Identification and functional characterization of brainstem cannabinoid CB2 receptors. Science 2005;310:329-32.

2. Peralta L, Agirregoitia E, Mendoza R, Expósito A, Casis L, Matorras R, et al. Expression and localization of cannabinoid receptors in human immature oocytes and unfertilized metaphase-II oocytes. Reprod BioMed Online 2011;23:372-9.

3. Li C, Bowe JE, Jones PM, Persaud SJ. Expression and function of cannabinoid receptors in mouse islets. Islets 2010;2:293-302.

4. Núňez E, Benito C, Pazos MR, Barbachano A, Fajardo O, González S, et al. Cannabinoid $\mathrm{CB} 2$ receptors are expressed by perivascular microglial cells in the human brain: an immunohistochemical study. Synapse 2004;53:208-13.

5. Fede C, Albertin G, Petrelli L, Sfriso MM, Biz C, De Caro R, et al. Expression of the endocannabinoid receptors in human fascial tissue. Eur J Histochem 2016;60:2643.

6. Bermúdez-Silva FJ, Suárez J, Baixeras
E, Cobo N, Bautista D, Cuesta-Muñoz $\mathrm{AL}$, et al. Presence of functional cannabinoid receptors in human endocrine pancreas. Diabetologia 2008;51:476-87.

7. Bermúdez-Silva FJ, Sanchez-Vera I, Suarez J, Settano A, Fuentes E, JuanPico P, et al. Role of cannabinoid CB2 receptors in glucose homeostasis in rats. Eur J Pharmacol 2007;565:20711.

8. Malenczyk K, Keimpema E, Piscitelli F, Calvigioni D, Biörklund P, Mackie $\mathrm{K}$, et al. Fetal endocannabinoids orchestrate the organization of pancreatic islet microarchitecture. PNAS 2015;112:E6185-94.

9. Starowicz KM, Cristino L, Matias I, Capasso R, Racioppi A, Izzo AA, et al. Endocannabinoid dysregulation in the pancreas and adipose tissue of mice fed with a high-fat diet. Obesity 2008; 16: 553-65.

10. Merkwitz C, Pessa-Morikawa T, Lockhead P, Reinhard G, Sakurai M, Iivanainen A, et al. The CD34 surface antigen is restricted to glucagonexpressing cells in the early developing bovine pancreas. Histochem Cell Biol 2011;135:59-71.

11. Li C, Jones PM, Persaud SJ. Role of the endocannabinoid system in food intake, energy homeostasis and regulation of the endocrine pancreas. Pharmacol Ther 2011;129:307-20.

12. Carlsson GL, Scott Heller R, Serup P, Hyttel P. Immunohistochemistry of pancreatic development in cattle and pig. Anat Histol Embryol 2010;39: 107-19.

13. LeBlanc S. Monitoring metabolic health of dairy cattle in the transition period. J Reprod Dev 2010;56:S29-35.

14. Roche JR, Blache D, Kay JK, Miller DR, Sheahan AJ, Miller DW. Neuroendocrine and physiological regulation of intake with particular reference to domesticated ruminant animals. Nutr Res Rev 2008;21:20734.

15. Mbvundula EC, Bunning RAD, Rainsford KD. Arthritis and cannabinoids: HU-210 and Win-55,212-2 prevent IL- $1 \alpha$-induced matrix degradation in bovine articular chondrocytes in-vitro. J Pharm Pharmacol 2006;58: 351-8.

16. O'Dowd JF, Stocker CJ. Endocrine pancreatic development: impact of obesity and diet. Front Physiol 2013;4:170.

17. Fonseca BM, Correia-da-Silva G, Taylor AH, Konje JC, Bell SC, 
Teixeira NA. Spatio-temporal expression patterns of anandamide-binding receptors in rat implantation sites: evidence for a role of the endocannabinoid system during the period of placental development. Reprod Biol Endocrinol 7:121.

18. Brusco A, Tagliaferro PA, Saez T,
Onaivi ES. Ultrastructural localization of neuronal brain CB2 cannabinoid receptors. Ann N Y Acad Sci 2008;1139:450-7.

19. Leterrier C, Bonnard D, Carrel D, Rossier J, Lenkei Z. Constitutive endocytic cycle of the CB1 cannabinoid receptor. J Biol Chem 2004;279:
36013-21.

20. Mercati F, Dall'Aglio C, Pascucci L, Boiti C, Ceccarelli P. Identification of cannabinoid type 1 receptor in dog hair follicles. Acta Histochem 2012; 114:68-71. 